\title{
An analysis of career advancement among engineers in manufacturing organizations
}

\author{
Ramayah Thurasamy \\ School of Management, Universiti Sains Malaysia, Penang, Malaysia \\ May-Chiun Lo \\ Faculty of Economics and Business, Universiti Malaysia Sarawak, Sarawak, \\ Malaysia, and \\ Adida Yang Amri and Noorhayati Noor \\ School of Management, Universiti Sains Malaysia, Penang, Malyasia
}

\begin{abstract}
Purpose - This research aims to study the effect of gender, supervisors' support, and tenure of service on objective and perceived career advancement among engineers employed in Malaysian manufacturing organizations in Northern Peninsular Malaysia. It begins by noting the centrality of inequality in gender and career advancement and also aims at providing a direct picture of tenure of service, which is among the factors least looked at when analyzing career advancement. The study also attempts to analyze the supervisor's support in relation to career advancement. Moderating the elements above are the demographic variables such as age, marital status, education level, and the location of the tertiary education institution.
\end{abstract}

Design/methodology/approach - By using a judgemental sampling method, a total of 158 engineers from ten multinational manufacturing companies were identified for this study.

Findings - The findings suggest that career advancement is very much related to gender, supervisor's support, and service tenure. It was also noted that women in male-dominated occupations, which is in this case the engineering field, tend to be subjected to the problems of performance pressures, social isolation, and stereotyping.

Practical implications - This study's framework has allowed for a better understanding of how perceptions are formed and the mechanisms linking these variables to the career advancement. This study perhaps is the first that has systematically attempted to integrate the various constructs as mentioned and employees' career advancement in organizations.

Originality/value - There is a gap in the literature concerning how demographic factors influence career advancement. This study has revealed that there is no clear distinction between career advancement and marital status for either male or female engineers as the statistical result disclosed no significant differences in marital status as a moderating element to the independent variables.

Keywords Career advancement, Gender, Supervisor's support, Service tenure, Demographics, Manufacturing industries

Paper type Research paper

An analysis of career advancement

Introduction

The interest in career advancement could be related to the theory of "survival of the fittest." Every career-minded individual is probably focused on wanting to know the "recipe," or factors that would allow them to be the fittest, or at least be among the fittest, to compete in the corporate jungle (Farmer, 1997). The thirst for career advancement is unquenchable and thus has led to many researchers spending time and effort analyzing

International Journal of Commerce and Management Vol. 21 No. 2, 2011 pp. $143-157$

(C) Emerald Group Publishing Limited 1056-9219 